\title{
Nuclear Energy Research Initiative (NERI) Quarterly Progress Report
}

\section{Feasibility Study of}

Supercritical Light Water

Cooled Reactors for Electrical

Power Production

Quarter 5 Report

October - December, 2002

Philip MacDonald

Dr. Jacopo Buongiorno

Cliff Davis

Dr. J. Stephen Herring

Dr. Kevan Weaver

January 2003

Idaho National Engineering and Environmental Laboratory Bechtel BWXT Idaho, LLC 


\title{
NUCLEAR ENERGY RESEARCH INITIATIVE (NERI) QUARTERLY PROGRESS REPORT
}

\section{Feasibility Study of Supercritical Light Water Cooled Reactors for Electric Power Production}

\author{
Project IWO No. SF9000106 \\ Project No. 2001-001

\section{Quarter 5 Report October - December, 2002}

\author{
Submitted by: \\ Idaho National Engineering and Environmental Laboratory (INEEL) \\ Philip MacDonald, Dr. Jacopo Buongiorno, Cliff Davis, \\ Dr. J Stephen Herring, and Dr. Kevan Weaver \\ Telephone: 208-526-3288 \\ Fax: 208-526-2930 \\ Email: pem@inel.gov
}

Collaborating Organizations:

Massachusetts Institute of Technology

Principal Investigators: Professor Ron Latanision and Dr. Bryce Mitton

University of Michigan

Principal Investigator: Professor Gary Was

Westinghouse Electric Company

Principal Investigators: Drs. Luca Oriani, Mario Carelli, and Dmitry Paramonov, and Lawrence Conway

Submitted on: January 31, 2003 


\section{Project Description}

The overall objective of this project is to evaluate the feasibility of supercritical light water cooled reactors for electric power production. The use of light water at supercritical pressures as the coolant in a nuclear reactor offers the potential for considerable plant simplification and consequent capital and O\&M cost reduction compared with current light water reactor (LWR) designs. Also, given the thermodynamic conditions of the coolant at the core outlet (i.e. temperature and pressure beyond the water critical point), very high thermal efficiencies for the power conversion cycle are possible (i.e. up to about $45 \%$ ). Because no change of phase occurs in the core, the need for steam separators and dryers as well as for BWR-type re-circulation pumps is eliminated, which, for a given reactor power, results in a substantially shorter reactor vessel and smaller containment building than the current BWRs. Furthermore, in a direct cycle the steam generators are not needed. If no additional moderator is added to the fuel rod lattice, it is possible to attain fast neutron energy spectrum conditions in a supercritical water-cooled reactor (SCWR). This type of core can make use of either fertile or fertile-free fuel and retain a hard spectrum to effectively burn plutonium and minor actinides from LWR spent fuel while efficiently generating electricity. One can also add moderation and design a thermal spectrum SCWR that can also burn actinides. The project is organized into three tasks:

Task 1. Fuel-cycle Neutronic Analysis and Reactor Core Design (INEEL). For the fast-spectrum SCWR, metallic (dispersion type), and oxide fertile fuels will be investigated to evaluate the void and Doppler reactivity coefficients, actinide burn rate, and reactivity swing throughout the irradiation cycle. For the thermal-spectrum SCWR, a variety of fuel and moderator types will be assessed.

Task 2. Fuel Cladding and Structural Material Corrosion and Stress Corrosion Cracking (University of Michigan and MIT). MIT will use an existing supercritical-water loop to conduct corrosion experiments in flowing supercritical water. A high temperature autoclave containing a mechanical test device will be built in Year 1 and operated in Years 2 and 3 at the University of Michigan to collect stress-corrosion cracking data. The data from both universities will be used to identify promising structural and fuel cladding materials and develop appropriate corrosion and stress corrosion cracking correlations.

Task 3. Plant Engineering and Reactor Safety Analysis (Westinghouse and INEEL). The optimal configuration of the power conversion cycle will be identified. Particular emphasis will be given to the applicability of current supercritical fossil-fired plant technology and experience to a direct-cycle nuclear system. A steady-state sub-channel analysis of the reactor core will be undertaken with the goal of establishing power limits and safety margins under normal operating conditions. Also, the reactor susceptibility to coupled neutronic/thermal-hydraulic oscillations will be evaluated. The response of the plant to accident situations and anticipated transients without scram will also be assessed.

\section{Progress on Task 1}

INEEL Neutronic Analyses. We have used MOCUP, a combination of MCNP4B and Origen2, to model the consumption of fissile material and the buildup of fission products and actinides during irradiation in a prototypical thermal spectrum SCWR with solid moderator material. The model consists of 40 axial fuel zones along the $427 \mathrm{~cm}$ rod height. The model includes the axial variation in the coolant density and has a two-zone variation in the fuel enrichment, $4.0 \mathrm{wt} \%{ }^{235} \mathrm{U}$ in the lower half and $4.2 \mathrm{wt} \%$ in the upper half of the rod. 
We are now in the process of benchmarking the current MOCUP calculations against previous MCNP beginning of life calculations. Our preliminary analyses indicate that the fuel may be reactivity limited to approximately 400 effective fuel power days. However, we believe that judicious choices of fixed moderation, inlet coolant flow and axial enrichment zoning will allow that burnup limit to be significantly increased. Nevertheless, it appears that the solid moderator designs previously reported in this NERI project may require considerably higher enrichments and not be economically viable.

Core design. Because depletion calculations show that the core design with solid moderator rods would require much higher enrichment levels to achieve an acceptable burnup at discharge, in this quarterly we have revisited the water-rod approach firstly proposed in Japan and Europe. In the Japanese design, moderation is provided by a descending flow of cold water in square boxes within the fuel assemblies. The moderator mixes with the cold coolant and flows back up in the fuel channels, from where it is sent directly to the turbine. The main issues for this approach are the need for a complicated coolant flow path within the vessel, and the mechanical connection of the fuel assemblies to the upper support plate. A conceptual design in which the water rods extend out of the fuel assembly and latch to the upper core plate has been developed at the INEEL that should solve both issues.

Also, a novel design based on small 19-pin hexagonal fuel assemblies has been developed in which the water moderator flows down in the inter-assembly gap and then back up in the fuel channels. The assembly duct has no structural function, is made of $\mathrm{Zr}-2.5 \mathrm{Nb}$ and is insulated on the inner surface to prevent corrosion. The fuel-cladding material is assumed to be an ODS steel, which should have good corrosion and mechanical properties. The neutronic calculations show that LWR-like burnup levels could be achieved with an acceptable increase in the enrichment. Due to the moderator density profile in the inter-assembly gap no enrichment zoning is needed to flatten the axial power profile, while the enrichment needs to be varied from pin to pin to flatten the local peaking. Finally, the temperature distribution within the assembly was evaluated and is deemed acceptable.

\section{Progress on Task 2}

Identification of Promising Materials. A meeting with representatives of INEEL was held at MIT in October to discuss the alloys to be assessed. During this meeting, a decision was made to expand both the matrix of materials to be tested and the existing system at MIT. System modifications will be accomplished to: (i) upgrade the control instrumentation, (ii) incorporate improved monitoring and control of the fluid chemistry, and (iii) increase system capacity. Ultimately, the intention is for the matrix to be expanded to include alloys from the following groups: oxide dispersion strengthened (ODS) alloys, austenitic stainless steels, ferritic/martensitic steels, and nickel-base alloys.

Experimentation at MIT. The experimental apparatus was modified to incorporate water cooling by external copper tubes. The cooling coils are positioned between the final two thermocouples. This was necessary to achieve the significant temperature drop needed to assess both sub- and supercritical temperatures simultaneously. A tube of the alloy to be tested is used as the autoclave, and microthermocouples are attached externally along the length of the vessel. Water at an elevated temperature and pressure is pumped into one end and permitted to cool as it transverses the tube. In general, once steady state is achieved, temperature fluctuations are minor $\left(+/-2^{\circ} \mathrm{C}\right)$. The most recent test employed a 1/8 inch OD (outside diameter) type 316 stainless steel tube. The sample was exposed for approximately 192 hours to non-deaerated 15 mega ohm water at a pressure of $3500 \mathrm{psig}$. The highest temperature achieved was in excess of $395^{\circ} \mathrm{C}$, which was lower than desired. A similar experiment with an alloy 625 tube is currently in progress and the temperature profile covers the range from $420^{\circ} \mathrm{C}$ to $300^{\circ} \mathrm{C}$. The preliminary analysis of the tube cross section suggests substantial oxide development at the highest temperature, with decreasing oxide development at lower temperatures as shown in Figure 1. The 
elemental analysis indicates the presence of an oxide layer and does not reveal the preferential elemental dissolution previously seen in SCW oxidation systems. That the tube reflects a decrease in the extent of oxidation as a function of decreasing temperature is in agreement with tests on mass loss coupons. After extended exposure (10-12 days) Type 316 stainless steel exhibits an average mass gain (standardized to area and exposure time) on the order of $0.0042 \mathrm{mg} / \mathrm{cm}^{2} /$ day at a temperature of $300^{\circ} \mathrm{C}$. This value increases to $0.0125 \mathrm{mg} / \mathrm{cm}^{2} /$ day at $500^{\circ} \mathrm{C}$.
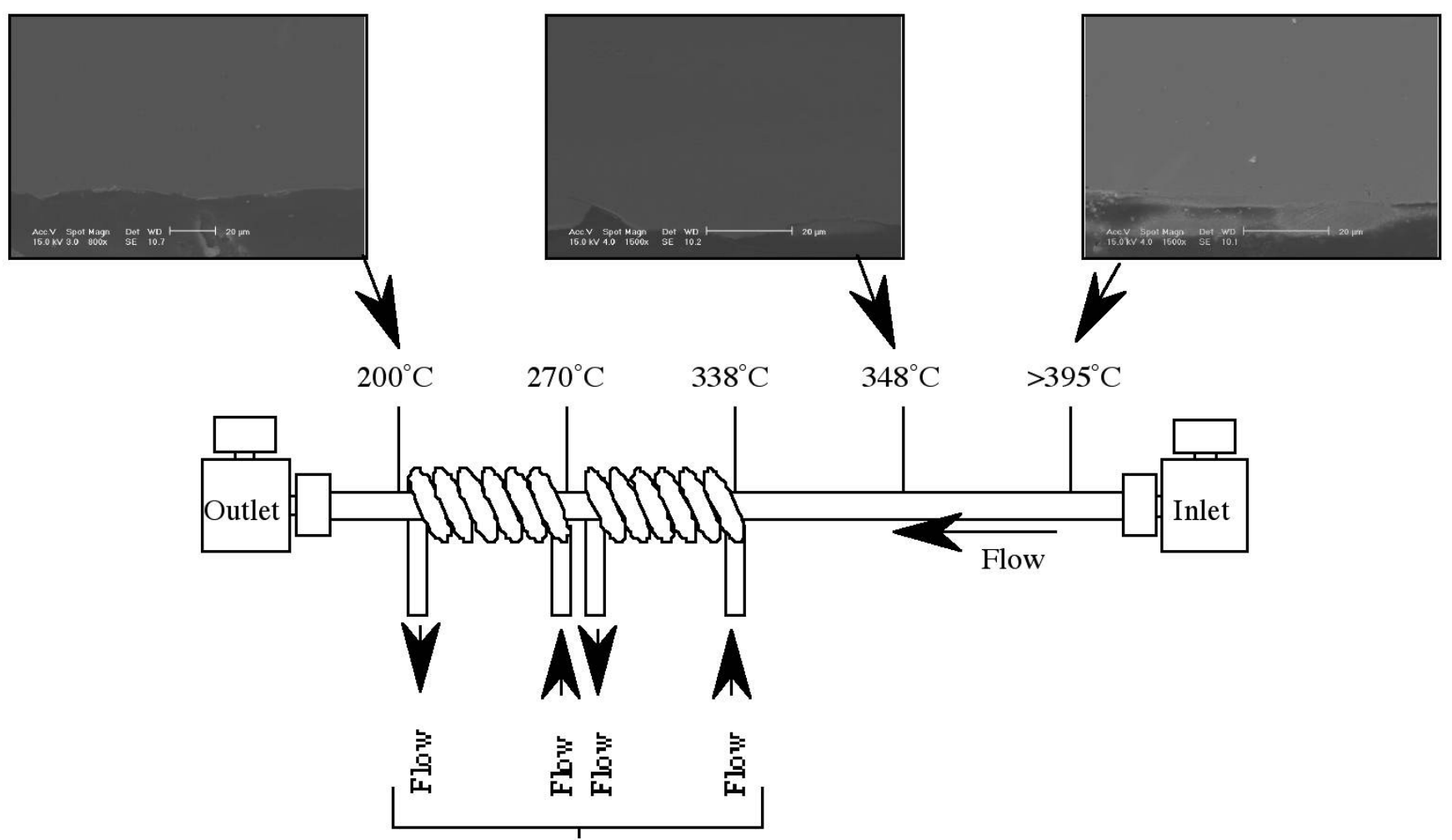

Cooling water lines

Figure 1. Experiment configuration, and micrographs of the tube cross-section at several temperatures after exposure to non-deaerated 15 mega ohm water for approximately 192 hours.

University of Michigan Experimentation. In the last report, we presented the result of a SCC tensile test performed on a 304L sample in aerated, supercritical water. Analysis of the test results showed that the SCW conductivity was high and that some stress variations appeared during loading of the sample. During this quarter, these phenomena have been studied. Also, the control of the oxygen content of the water was verified. Our results suggest that the conductivity increase recorded during the last test was most probably due to faulty behavior of the probes. It appears that the flow rate needs to be higher that 40 $\mathrm{ml} / \mathrm{min}$ to provide an accurate response of the probes. Since this flow rate is four times higher that the one we currently use (which is set by the requirement of maintaining the water temperature setting), there are two options: 1) change the probes or the probe setting to be able to work with a low flow rate, or 2) modify the loop in order to be able to increase the flow rate. Also, when a sample is strained in supercritical water, some stress variations appear. It was necessary to determine whether the sample experienced these variations or if they are due to some noise in the system. Several tests were performed with the aim of excluding any electronic noise due to use of the heating facility and the pump. It appears that these elements are not responsible of the variation recorded. 
Also, preparation of alloys for the next experiments started. Alloy 316L stainless steel material was characterized, heat treated, and machined for testing during this quarter. Alloy $316 \mathrm{~L}$ was selected as the first alloy to undergo testing from the list of alloys presented in the first Annual Report based on the fact that we are most familiar with 316L and that it is easier to prepare and heat treat than most of the other alloys. Alloy 316L was also selected first in order to coincide with the set of corrosion experiments that MIT is performing. After some maintenance and several small changes to the system, an experiment with a sample of commercial purity $316 \mathrm{~L}$ was begun.

\section{Progress on Task 3}

Westinghouse Sub-channel Analyses. Westinghouse is developing a model for sub-channel analyses by modifying the VIPRE-01 code, as described in the first annual report. The first results will be provided in the second quarterly report. Also, a review of supercritical water heat transfer correlation has continued: different correlations and studies have been reviewed and updated results will also be included in the next quarterly report.

INEEL Reactor Safety Analyses. A RELAP5 model of the supercritical water reactor (SCWR) previously described in our Quarterlies was developed. The model represents the reactor vessel including the down-comer, lower plenum, core, upper plenum, and upper head. The core is modeled with three parallel channels, one representing a high-powered fuel bundle, one representing 155 average-powered fuel bundles, and one representing a low-powered fuel bundle. The heated length is divided equally into ten axial control volumes. Heat structures are used to represent fuel rods and moderator boxes in each core channel, as well as the reactor vessel wall and core barrel. A separate heat structure is used to model four hot rods in the high-powered fuel bundle. A calculation was performed to determine the steady-state thermal-hydraulic conditions at normal operating power. The values are consistent with the desired initial conditions. A version of RELAP5 was created that contained the Bishop et al. ${ }^{1}$ and the Koshizuka-Oka ${ }^{2}$ heat transfer to supercritical water correlations. The maximum cladding temperatures obtained with the Bishop and Koshizuka-Oka correlations were similar at a normalized power of 1.0. However, the two correlations predicted completely different trends with respect to power as shown in Figure 2. The Bishop correlation predicted that the maximum cladding temperature increased with power, while the Koshizuka-Oka correlation predicted that it decreased with power. The location of the maximum cladding

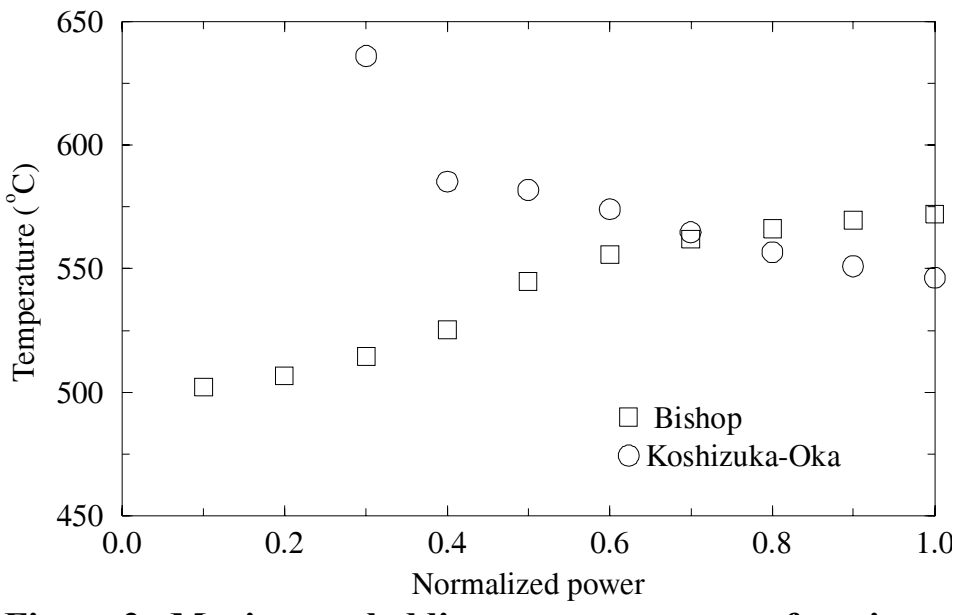

Figure 2. Maximum cladding temperature as a function of normalized power, with the power-to-flow ratio held constant.

${ }^{1}$ Bishop, A., A., R. O. Sandberg, and L. S. Tong, 1964, "Forced Convection Heat Transfer to Water near Critical Temperature and Supercritical Pressures," WCAP-2056-P, Part-III-B, February.

2 Koshizuka, S. and Y. Oka, 2000, "Computational Analysis of Deterioration Phenomena and Thermalhydraulic Design of SCR," Proceedings of the First International Symposium on Supercritical Watercooled Reactors, Design and Technology, November 6-9, University of Tokyo, SCR-2000, pp. 169-179. 
temperature also varied between correlations. These results strongly support the need for additional SCWR heat transfer measurements.

Calculations were then performed to investigate the effects of various parameters on the peak cladding temperature following a loss-of-feed-water event. The parameters investigated include the main feedwater coast-down time, occurrence of scram, auxiliary feed-water flow rate, and relief valve capacity. It was determined that faster scram insertion than normal for light water reactors or additional auxiliary feed-water flow will be required to meet the transient temperature limit of $840^{\circ} \mathrm{C}$. The short-term flow requirements can probably be met by a fast-acting pumped auxiliary feed-water system or possibly a passive system. An alternate approach would be to design the system so that the total loss of main feedwater is classified as an accident rather than a transient, such as Ishiwatari et al. ${ }^{3}$ did. However, it is unlikely that the USNRC would agree to reclassifying this transient from a Class II to a Class IV accident.

\section{Issues/Concerns}

There are no technical issues and the work has been within budget and on schedule. However, this project is badly under-funded and work will stop at some locations before the end of the year because of funding limitations.

3 Ishiwatari, Y., Y. Oka, and S. Koshizuka, "Safety analysis of a high temperature supercritical pressure light water cooled and moderated reactor," Nuclear Engineering Research Laboratory, The University of Tokyo. 


\section{Cost Performance}

INEEL

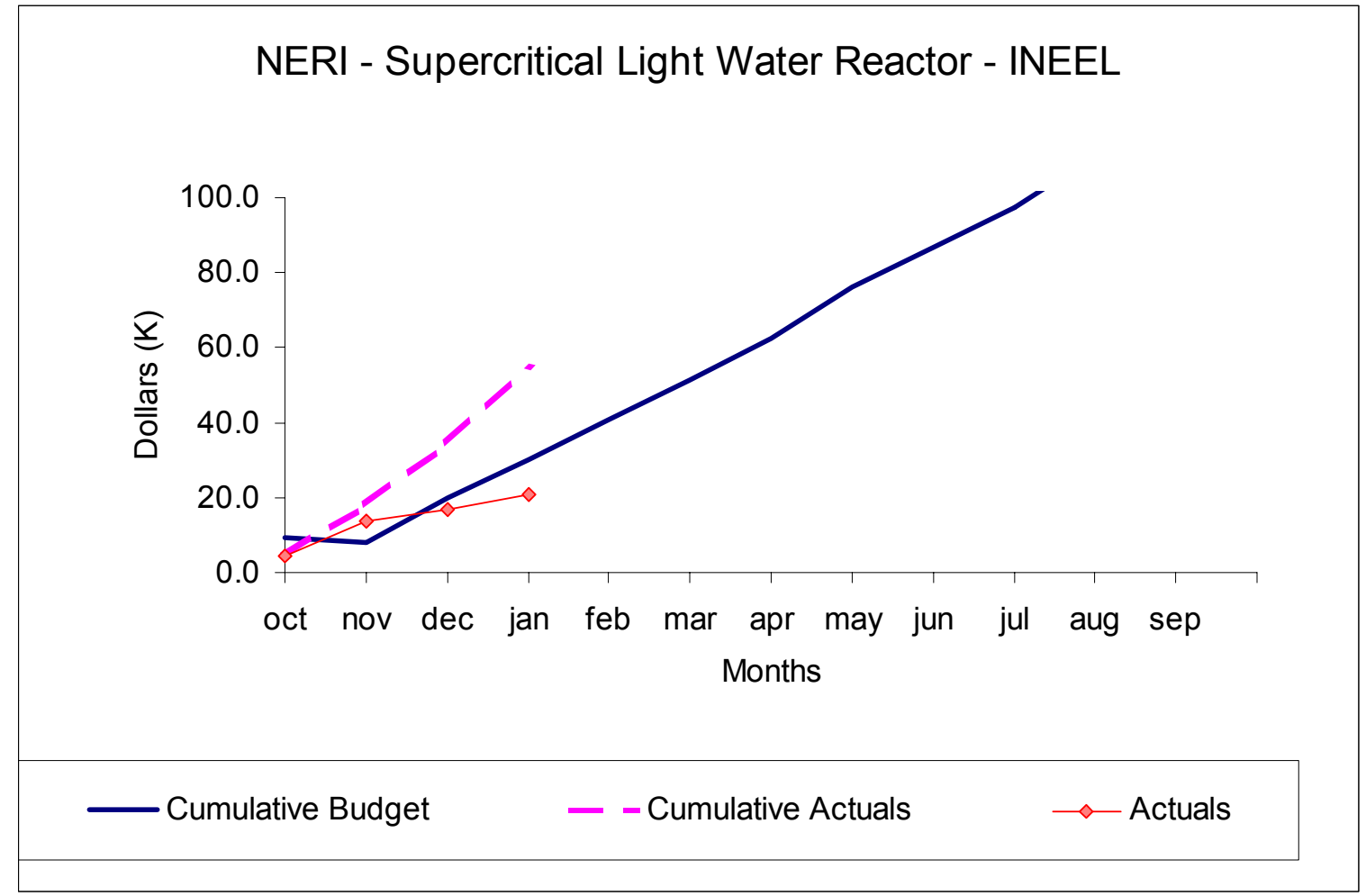

\section{MIT}

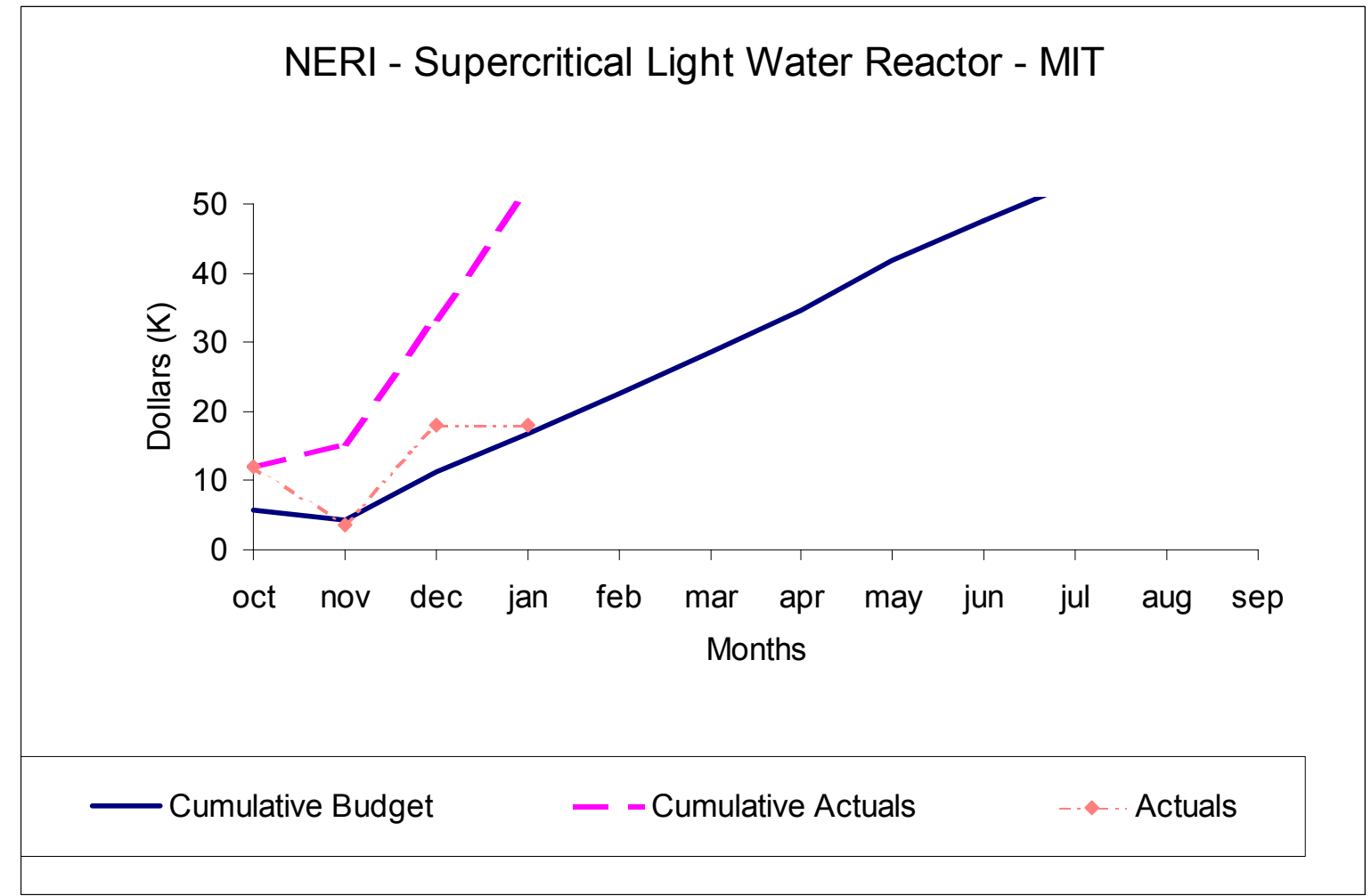




\section{University of Michigan}

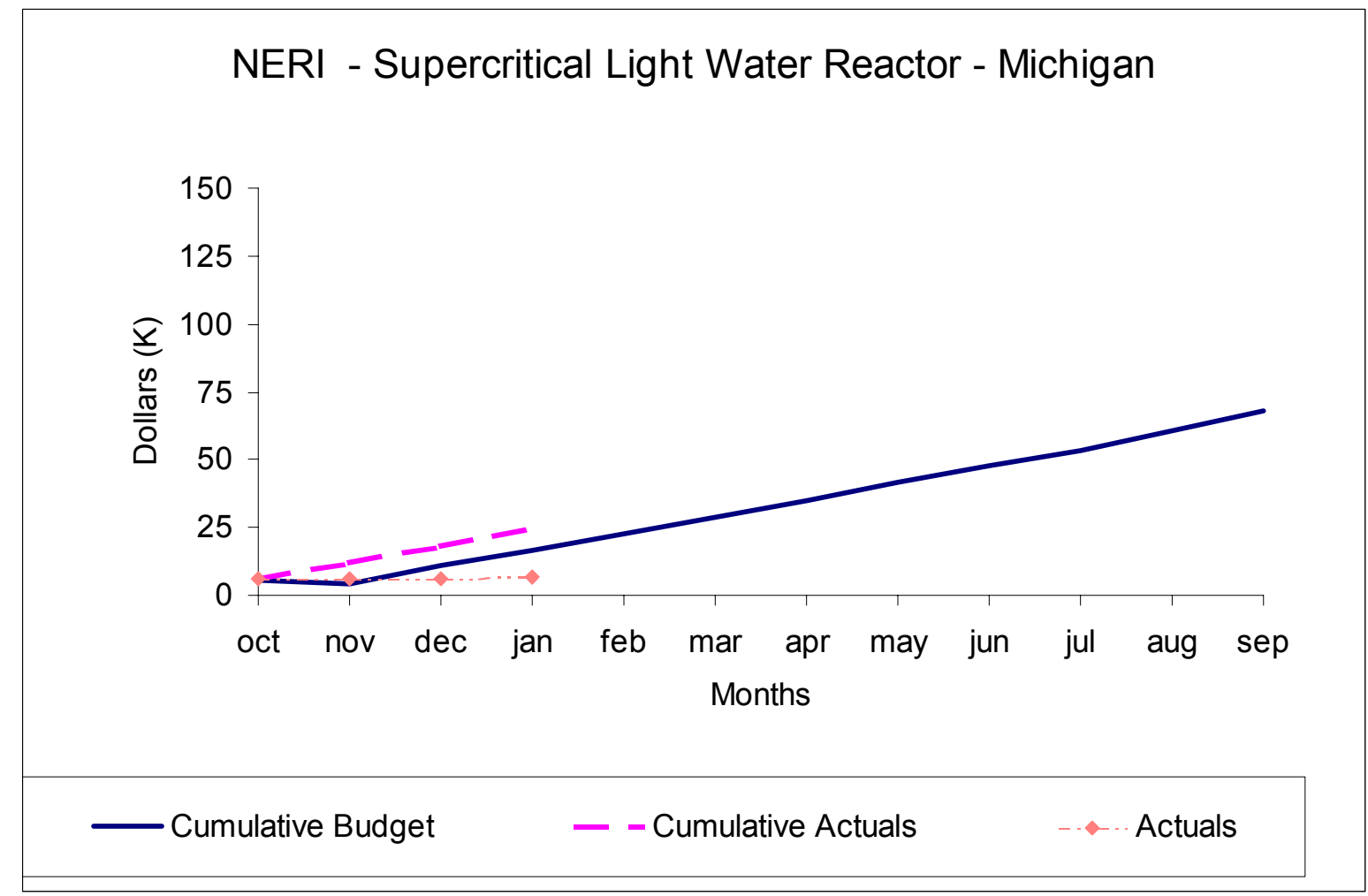

\section{Westinghouse Electric Co.}

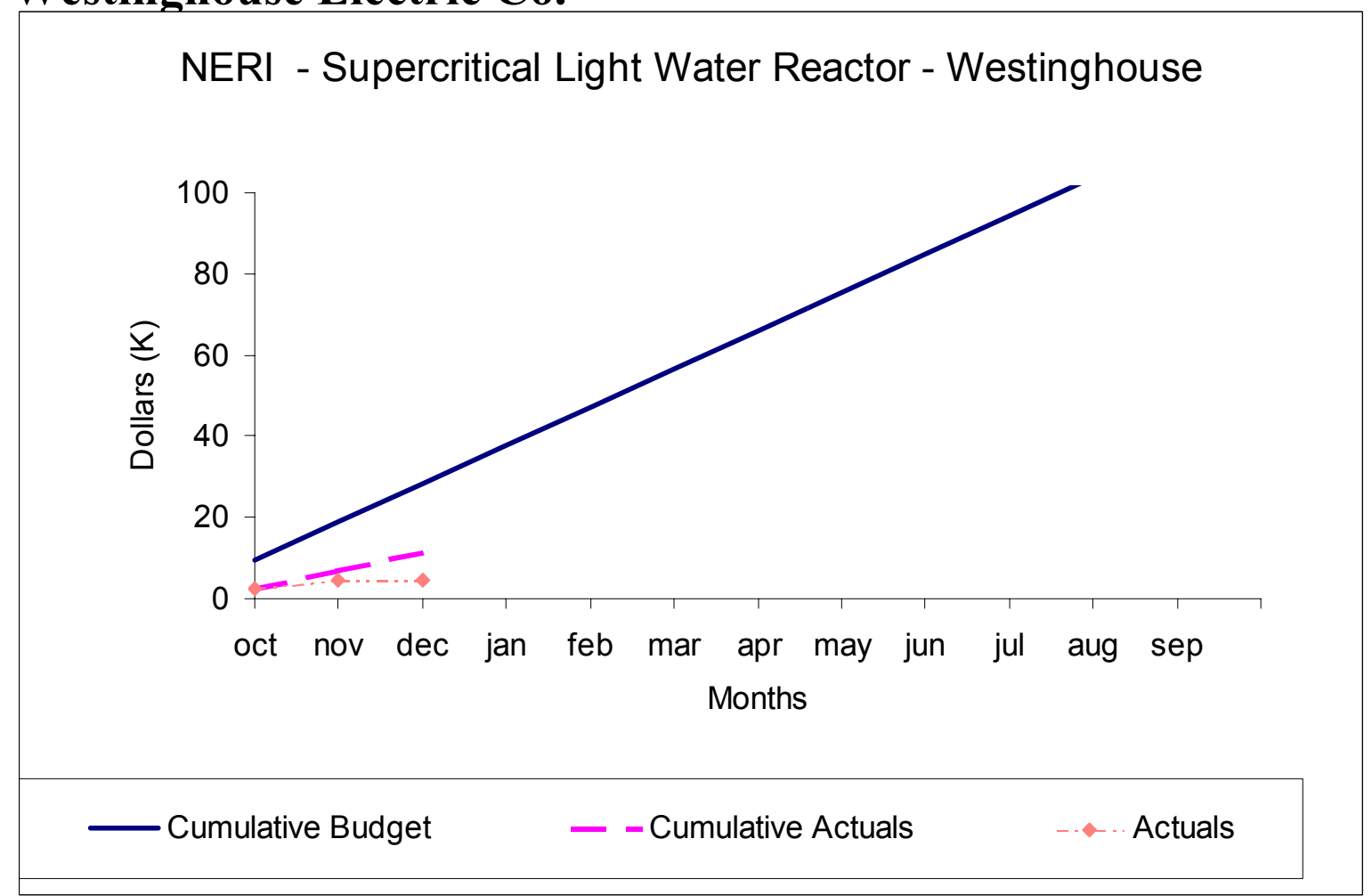




\section{Schedule Performance}

All tasks are on schedule per the original schedule below.

\begin{tabular}{lll}
\hline Task & Activity & Description \\
\hline Task 1 & $\begin{array}{l}\text { Fuel-cycle Neutronic Analysis and Reactor Core Design } \\
(\text { INEEL) }\end{array}$ \\
& 1.1 & Reactivity Swing Analysis \\
& 1.2 & Actinide Discharge and Isotopic Evaluation \\
& 1.3 & Reactivity Coefficient Calculations \\
& 1.4 & Peaking Factors and Reactor Control \\
& & \\
Task 2 & Fuel Cladding and Structural Material Corrosion and \\
& Stress Corrosion Cracking Studies (University of Michigan) \\
& 2.1 & Identification of Most Promising Materials \\
& 2.2 & Design and Construction of an Out-of-pile \\
& 2.3 & Supercritical Water Test Facility \\
& & Corrosion and Stress Corrosion Cracking \\
& Behavior of Candidate Materials \\
& 2.4 & Radiation Stability of Candidate Alloys \\
& 2.5 & Modeling of Corrosion and stress Corrosion \\
& & Cracking in Supercritical Water
\end{tabular}

Task 3 Plant Engineering and Reactor Safety Analysis (Westinghouse and INEEL)

3.1 Conceptual Design of the Reactor Coolant System (Westinghouse)

3.2 Definition of the Thermal/Mechanical Design

3.4 Evaluation of Coupled Thermalhydraulic/Neutronic Oscillations (INEEL)

3.5 Plant Configuration and Operation (Westinghouse)

3.6 Establish the Conceptual Design of Required Safety Systems and Define their Performance Parameters (Westinghouse)

3.7 Analysis of Anticipated Transients and Potential Accidents (INEEL)

3.8 Conceptual Layout of Reactor Containment, Fuel Handling, and Auxiliary Buildings (Westinghouse)

3.9 Economic Analysis (Westinghouse)

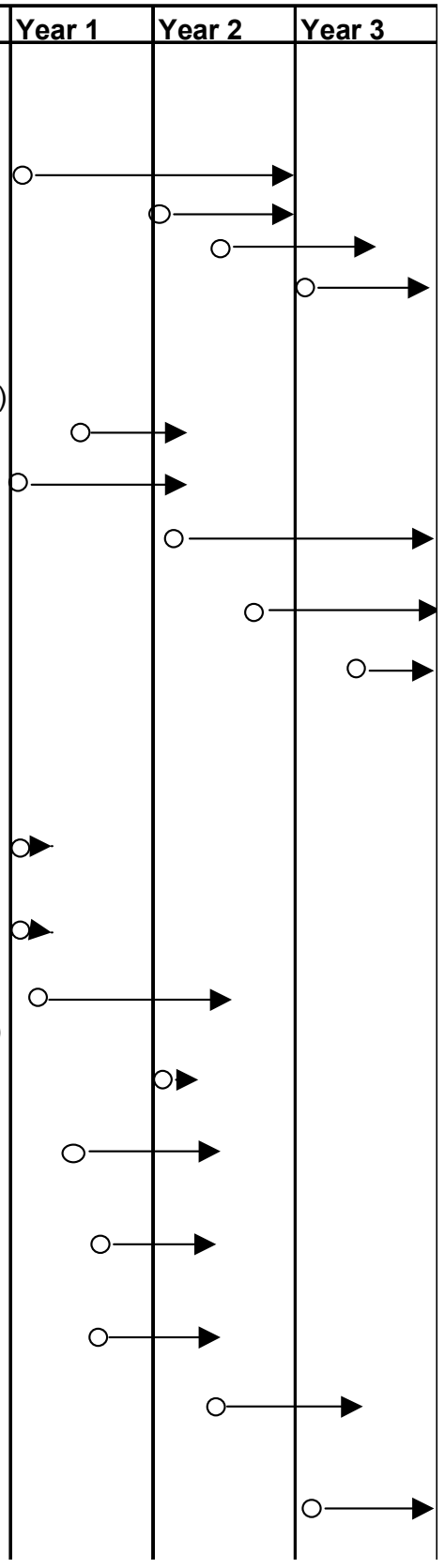

